\title{
Skin Managements and Diseases
}

\author{
Sahar S Atrees, ${ }^{1}$ Haba Mohamed Rabei, ${ }^{2 *}$ \\ ${ }^{1}$ The departments of biochemistry, Fayoum university, Egypt \\ ${ }^{2}$ The departments of zoology, Fayoum university, Egypt
}

\begin{abstract}
The skin is the largest organ of the body, accounting for about $15 \%$ of total adult body weight, it performs vital functions, including protection, against external, physical, chemical, biologic assailants through integumentary system composed of three layers, the epidermis, dermis, and subcutaneous tissue. The purpose of this article is to highlight upon some important interactions with the skin, these interactions have great important signs and diagnosed for many pathophysiology and skin diseases. Association between light, overweight, and neuropeptide and dermatologic conditions related to skin managements to these parameters will be impacted in this article.
\end{abstract}

Keywords: Skin, Light, Dermatology, Diseases

\section{Introduction}

The skin is organ of the body, accounting for $15 \%$ of total body weight, it performs many vital functions. ${ }^{1}$ Preventing of excess water loss from body and have a role in thermoregulation. The skin is continuous with the mucous membranes lining the body $\mathrm{S}$ surface. ${ }^{2}$ The skin is composed of three layers, the epidermis, dermis and subcutaneous tissue. ${ }^{2}$ The outer most level, epidermis, consists of a specific constellation of cells known as Keratinocytes, which function to synthesis keratin which is a long thread like protein with a protective role. The middle layer, the dermis, is made of fibrillar structural proteins known as collagen. The dermis lies on the subcutaneous tissue or, Panniculus. ${ }^{3}$ Which contain small lobes of fat cells called lipocytes. The thickness of these layers varies considerably, depending on the geographic location on the anatomy of the body. The eyelid, for example, has the thinnest layer of the epidermis, measuring less than $0.1 \mathrm{~mm}$, whereas the palm and soles of the feet have thickest epidermal layer, measuring about $1.5 \mathrm{~mm}$.

The dermis is thickest on back, where it is 30-40 times as thick as overlaying epidermis. ${ }^{1}$ Subcutaneous fat embryonically, toward the end of fifth month fat cells begin to develop in the subcutaneous tissue, these lobules of fat cells or lipocytes are separated by fibers septa made up of large blood vessels and collagens, the Panniculus varies in thickness depending on skin site. ${ }^{4}$

The subcutaneous tissue provides the body with functions as store house energy, hormone conservation take place in panniculus, converting and roster one into estrone by aromatase. Lipocytes produce leptin, a hormone that regulate body weight by way of the hypothalamus. ${ }^{3}$ The three layers of skin form an effective barrier to the external environment, allow the transmission of sensory information, and serve a significant role in maintaining homeostasis. The dynamic epidermis produces a protective outer layer of cornecytes as cells undergo the process of keriatization and terminal differentiation. Collagen and elastic filaments of dermal layer provide underlying tensile strength of skin, whereas the layer of subcutaneous fat provide a store of energy for the body.

The layers of skin are involved to light interactions and conversion of vitamin D also, have many hormones that relates to regulation of overweight. Finally full of many nerves that modulates many

\begin{tabular}{|l|l|}
\hline \hline Quick Response Code: & *Corresponding author: Haba Mohamed Rabei, The departments of zoology, science faculty, \\
Fayoum university, Egypt & Published: 28 October, 2021 \\
& Received: 18 October, 2021 \\
& Citation: Atrees SS, Rabei HM. Skin Managements and Diseases. Curr Trends Toxi Pharma Res. \\
\hline
\end{tabular}


important functions as sensation against many stimulus. From this view, speculate on special interaction of some parameter and molecules with the skin, may give hopeful information about pathophysiology of skin diseases and treatment.

\section{Skin Physiology: A D: Lightful Story}

Throughout revolution, exposure to sunlight and photosynthesis of vitamin D in the skin has been critical important for evolution of land vertebrates. ${ }^{5}$ Vitamin D is likely to be one of oldest if not the oldest hormone that has excited on earth. Emiliani huxleyi, a phytoplankton, that has survived in Sargasso sea (Atlantic ocean), unchanged for $>7500$ million years, produced a large amount of ergo sterol (provitamin D), that was $0.1 \%$ of dry weight, ${ }^{6}$ when organism exposed to simulated sunlight, the ergosterol was converted to previtamin D, which rapidly converted into vitamin D. ${ }^{6,7}$ Ergosterol acted as an ideal sunscreen to protect organism from UVB, and UVC, radiation which was most damaging to its UV-absorbing DNA, RNA, and protein. ${ }^{6,7}$ As life form ?s shifts left ocean and ventured onto land, they needed to adapt to the low calcium environment by developing a hormonal system to regulate the efficiency of intestinal and calcium absorption. furthermore, previtamin D was transformed into vitamin D this ejected out of furthermore previtamin D was transformed into vitamin D this ejected out of plasma membrane causing an increase of permeability of calcium ions into cell. Excessive exposure to sunlight will not result in vitamin D intoxication, because both previtamin D and vitamin D are photolyzed to several to no calcemic photoproducts.

Conversion of previtamin D (70 dehydrocholesterol) in plasma membrane into vitamin D processed only in the skin of most mammals, such as, amphibians, reptiles, all avian species, but birds are not able to make any vitamin D in skin covered with feathers, also Cats have no-7-dehydrocholesterrol in their skin and therefore cannot make vitamin $\mathrm{D}$, this fact may give new marker for vitamin D deficiencies by measuring amount of 7-dehydrocholestrol in their plasma membranes. There was a dramatic influence of many factors that affect managements of the skin to light related to vitamin D conversion, such as, latitude, temperature, clouds, clothes, aging. all of these factors will be discussed later in the discussion part.

\section{Overweight and Skin}

Overweight (obesity) is being recognized as a major public health problem in many countries. the prevalence of obesity, which is defined as a body mass index (BMI) of $30 \mathrm{Kg} / \mathrm{m}^{2}$ or greater has increased in populations over the past 30 years. ${ }^{8,9}$ the impact of obesity on the skin has received minimal attention. obesity results from both environmental and genetic factors. Approximately $60 \%$ to $70 \%$ of variants in BMI can be attributed to environmental and $30 \%$ to $40 \%$ of variance in BMI can be attributed to genetics, en- vironmental factors contain dietary choices, socioeconomic status, behavioral factors and reduce physical activity. Genetic obesity results from mutation in genes involve in food intake regulations. ${ }^{10}$ Some disorders diseases in the skin due to obesity will be summarized in Table 1. Obesity is responsible for a variety of changes in the skin, skin manifests barrier functions, gland production, collagen structure and function, wound healing, micro circulation, so obesity is implicated to many dermatologic diseases, that leading to the fact that clinical feature associate with obesity and managements of skin needed to spotlight and study.

Table 1: Skin disorders in obesity.

\begin{tabular}{|l|l|}
\hline \multicolumn{1}{|c}{ Disorders } & \multicolumn{1}{|c|}{ characterized symptoms } \\
\hline \multirow{5}{*}{ : Insulin resistance } & - Insulin resistance syndrome \\
\cline { 2 - 2 } & Acanthosis nigricans \\
\cline { 2 - 2 } & Acrochordons \\
\cline { 2 - 2 } & Keratosis pilaris \\
\cline { 2 - 2 }$:$ Inflammatory & Hyperandrogenesis \\
\cline { 2 - 2 } & Hirsutism \\
\hline \multirow{4}{*}{$:$ Metabolic } & - Hidradenitis suppurativa \\
\cline { 2 - 2 } & Psoriasis \\
\hline \multirow{5}{*}{$:$ Infectious } & - Tophaceous gout \\
\hline & - Intertrigo \\
\cline { 2 - 2 } & Candida \\
\cline { 2 - 2 } & Dermatophytes \\
\cline { 2 - 2 } & Folliculitis \\
\hline
\end{tabular}

\section{Neuropeptides and the Skin}

The cutaneous peripheral nervous system (PNS) plays a pivotal role in skin homestatis and diseases, the central nervous system (CNS) is directly via efferent nerves or CNS-derived mediators or indirectly via the adrenal gland, or immune cells, connected to skin function. ${ }^{11}$ Figure 1 and Figure 2 show the nerves in the skin and functions. Sensory as well as autonomic sympathetic nerves influences a variety of physiological and pathophysiological function in the skin. physiological such as, embryogenesis, vasocontraction, vasodilation, temperature, barrier function, secretion, growth, differentiation nerve growth. Pathophysiological, such as, inflammation, immune defense, apoptosis, proliferation, wound healing. ${ }^{12,13,14}$ Various neuropeptides will be reported here as enkephalins, Vaso active intestinal polypeptide (VIP), primary adenylated cyclase activating polypeptide (PACAP), POMC. another important neuropeptide will be shown in Table 2. These interactions are mediated primary afferent as well as autonomic nerves, which release neuromodulators and activates specific receptors on many target cells in the skin, a dense network of sensory nerves releases peptides, that participates in many properties of skin function. 
Table 2: Selected neuropeptide and their functions in the skin.

\begin{tabular}{|l|l|l|l|}
\hline Categrory & Receptors & physiology and anatomy & comments \\
\hline Acetylcholine & $\begin{array}{l}\text { nicotinergic and } \\
\text { muscarinal M ACHR, N } \\
\text { ACHR acetylcholine }\end{array}$ & $\begin{array}{l}\text { Acetonomic cholinergic nerves } \\
\text { keratinocytes, lymphocytes } \\
\text { melanocytes }\end{array}$ & $\begin{array}{l}\text { Itch- in dermatic, regulate prolifrtion, adhe- } \\
\text { sion, migration }\end{array}$ \\
\hline $\begin{array}{l}\text { Corticotropin Releasg } \\
\text { Hormons (CRH) }\end{array}$ & CRH-R1, R2 & $\begin{array}{l}\text { Crhr1: keratinocytes mast cells } \\
\text { Crhr2: bone marrow mast cells }\end{array}$ & $\begin{array}{l}\text { Release histamine VEGF, cytokines immune } \\
\text { reactive down regulate stress and infection } \\
\text { regulate pigment }\end{array}$ \\
\hline Endocannabinoids (CB) & Cb1, cb2 receptors & $\begin{array}{l}\text { Nerves, T cells macrophages } \\
\text { receptors keratinocytes skin } \\
\text { appendages }\end{array}$ & $\begin{array}{l}\text { Inhibit cytokines during immune response, } \\
\text { down regulate release of IL-1, antipruitic }\end{array}$ \\
\hline Interleukin-31 & IL-31R heterodimer & Keratinocyte sensory nerve & Skin inflammation by T cells induce itching \\
\hline Kinins & $\begin{array}{l}\text { Bradykinin receptor } \\
\text { B1, B2 }\end{array}$ & $\begin{array}{l}\text { Endothelial cells immunocytes } \\
\text { keratinocytes sensory nerves }\end{array}$ & $\begin{array}{l}\text { Induce pain over pruritus induce MAP kinase } \\
\text { phospholation in keratinocytes }\end{array}$ \\
\hline $\begin{array}{l}\text { Opioids } \\
\text { Propimelanocorting } \\
\text { endorphins dynophins }\end{array}$ & $\begin{array}{l}\text { MKS-opioid receptors } \\
\text { Opioids receptors }\end{array}$ & $\begin{array}{l}\text { Sensory nerves keratinocytes T } \\
\text { cells, B cells }\end{array}$ & $\begin{array}{l}\text { Antipruitic effect, donot provoke itch upon } \\
\text { injection, intradermal appl }\end{array}$ \\
\hline
\end{tabular}

List of abbreviation of table 2

ACHR: Acetyl Choline Receptor; IL: Interleukin; JMMk-opoid: Peptidergic Neurotransmitter; VECF: Vascular Endothelial Growth Factors; MAP: Mitogen Activate Protein; VIP: Vasoactive Intestinal Polypeptide.

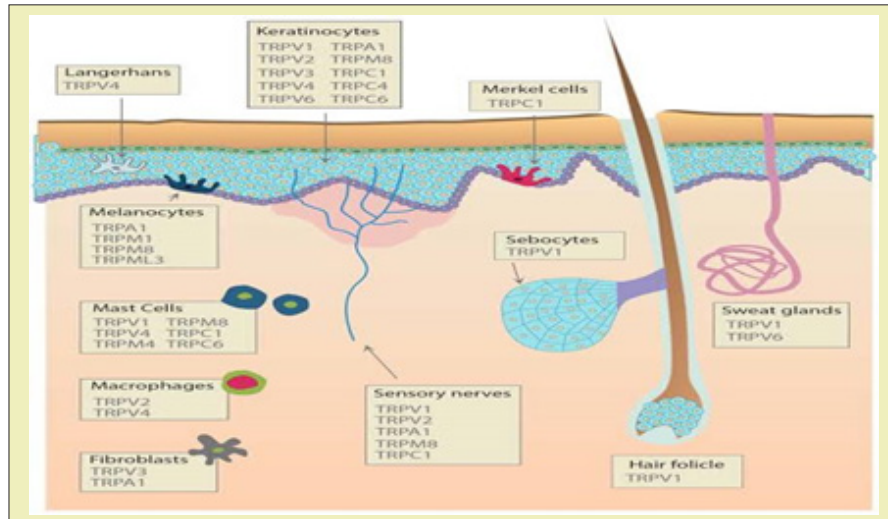

Figure 1: The cutanoues nerves and skin cells.

\section{Vasoactive intestinal polypeptide (VIP)}

VIP is a 28 amino acid peptide that derived from precursor mRNA, that also encodes histamine, methionine (PHM). ${ }^{15}$ In the skin, VIP, like immune reactivity, was detected in nerve fibers associated with dermal vessels, glands, such as, sweat, apocrine, Meibomian glands, hair follicle, and Markel cells in the skin, VIP mediate vasodilation, ${ }^{16}$ and proliferation, induce migration of keratinocytes that important in wound healing ${ }^{17}$ And Psoriasis. ${ }^{18}$

Primary adenylated cyclase activating polypeptide (PACAP)

PACAP is a new member of the VIP/secretin peptide family. ${ }^{19}$

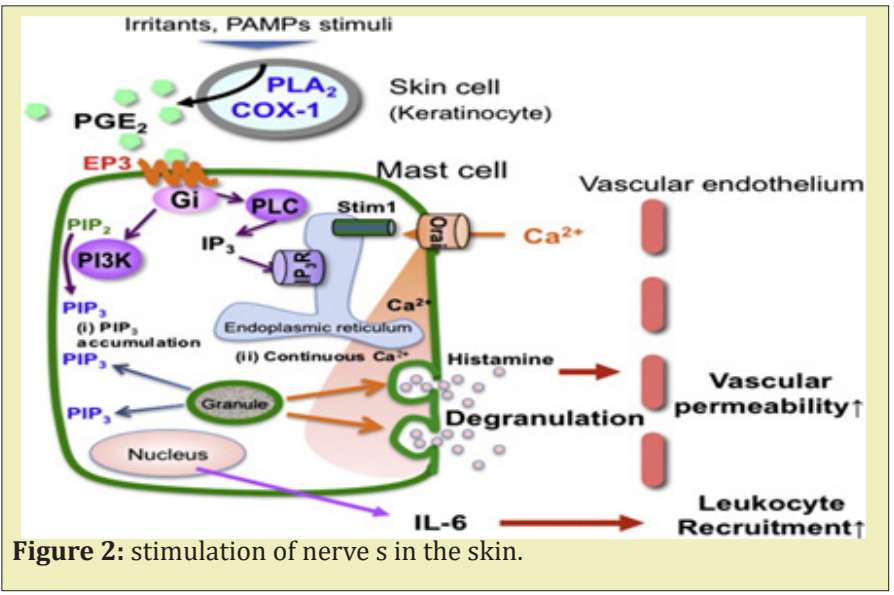

Two forms can be distinguished, PACAP-38, and truncated product PACAP-27, both of which are derived from a 176-precursor protein $(19.5 \mathrm{KDa})$ by posttranslational cleavage. ${ }^{20}$ PACAP is located in many tissues, including skin, PACAP is present in sensory and autonomic fiber of dorsal root ganglia, the spinal cord and, adrenal gland, suggesting involvement in sensory and nociceptive pathways. In the skin, PACAP was detected in sensory nerve fibers ${ }^{21}$ coexisting with VIP, SP, or CGRP respectively, all of which may play an important role in inflammatory skin diseases like Psoriasis, Urticaria, or atopic dermatitis. ${ }^{22}$ PACAP -38 appears to be enhanced in lesional skin of Psoriasis patients, indicating that neuropeptide has a role in the pathophysiology of this skin disease, the peptide 
level was significantly lower in non-lesioned Psoriatic skin than in lesioned Psoriasis skin, but was twice as much as in normal skin PACAP appears to be involved in cutaneous inflammation e.g., releasing histamine from mast cells. ${ }^{23}$ Several observation supporting idea that PACAP modulate inflammatory responses in the skin, and play an essential role in nociceptive transmission in the skin.

\section{Enkephalins}

The endogenous opioid peptides (Met)-enkephalins and (Leu)-enkephalins are known to suppress a number of elements of the immune response, including antimicrobial resistance, antibody production, and delayed-type hypersensitivity. ${ }^{24}$ In the skin, application of (Met)-encephalin induced a flare reaction, reducible by pretreatment with antihistamine, suggesting both histamine-and histamine independent involvement of enkephalins in neurogenic inflammation. ${ }^{25}$ (Met)-enkephalin induced inflammation of dermal lymphocytes, monocytes, and macrophages and enkephalins protect against tissue damage caused by Hypoxia and inhibit different ian and proliferation of keratinocytes. ${ }^{26}$ Increased amount of enkephalins were reported in the lesional skin of PSorasis patients, enhanced levels of enkephalns are reduced in parallel with clinical improvement induced by a topical vitamin D analog and a corticosteroids. Thus, because enkephalns can modulate epidermal different ian and inflammatory processes, these finding indicate that enkephalins may play role in the pathogenesis of Psoriasis. ${ }^{27}$ Table
2 Summarizes other neuropeptide and interactions with the skin.

\section{X: Neurotrophins and skin}

The mammalian skin expresses a variety of neurotrophic growth factors such as, nerve growth factor( NGF), brain derived nerve growth factor ( BDNF), neurotrophin -3 and neurotrophin 4/5 ( NT -3, NT 4/5), which are essential for growth, proliferation and maintenance of nerves. ${ }^{28,29}$ Cutaneous neurotrophins are expressed by sensory and sympathetic neurons and non-neuronal cells, thereby regulating various biologically modulating such as, nociceptoion, prioception, mechanoreception, nerve growth, and development, apoptosis, epidermal homeostasis and inflammation, hair growth. Several observation suggesting that neurotrophins participate in neuroimmunological network, such as in cutaneous application of neuropeptides such as, cholicystokinine-8 enhances NGF expression in the skin, ${ }^{30}$ recently enhanced expression of NGF m RNA was described in mast cells and keratinocytes, less in fibroblasts of patients with atopic dermatitis. ${ }^{31} \mathrm{NGF}$ level are increased in inflammatory skin disease, as Psoriasis, also stimulate degranulation of mast cells. NGF is regulated in patients with atopic dermatitis, in which it may contribute to Pruitus, mast cell stimulation eosinophil activation and keratinocytes dysfunction. ${ }^{30}$ This may account for a role of NGF a disease in which these cells are activated in atopic dermatitis. a number of cutanoues nerve system contribute to pathogenesis of skin will be shown in Table 3.

Table 3: disorders of skin related to neuropeptides.

\begin{tabular}{|l|l|l|}
\hline \multicolumn{1}{|c|}{ Skin disorders } & \multicolumn{1}{|c|}{ Neuropeptides } & \multicolumn{1}{c|}{ Pathophysiology } \\
\hline Urticaria & Neurokinins, Sp, CGRP & induce mast cell, release histamine, cytokines TNF- $\propto$ \\
\hline Psoriasis & VIP, SP, CGRP, PACAP-38 & Immunoreactivity, atopic dermatitis \\
\hline Atopic dermatitsis & Takykinin & Neurogenic inflammation, pruritic erythema wheal, flare \\
\hline $\begin{array}{l}\text { Immediate and delayed } \\
\text { hypersensitivity }\end{array}$ & Langerhans cell CHS & Immunohistochemical epidermal antgen, erythema, swalling, pain \\
\hline Wond-healing & High conc of SP & $\begin{array}{l}\text { Growth factors production, cell proliferation, cytokines vascular } \\
\text { permeability }\end{array}$ \\
\hline Pruritus & Kinin, kallikreins, protease tryptase, \\
cytokine, protons & Malignance infection metabolic disorder edema, erythema \\
\hline
\end{tabular}

List of abbreviation of table 3:

SP: Substance Peptide; CHS: Contact Hypersensitivity; CGRP: Calcitonin Gene Relate Peptide

\section{Discussion and Further Directions}

The skin is the largest organ of the body, performing many functions, including protection, thermoregulation, etc., pathophysiology of skin is taken an important view in last decades especially, pathophysiology with light, overweight, neuropeptides. The following discussion investigated those parameters, opening new therapy and treatments for many diseases. Some people are susceptible than others to developing vitamin D deficiency, defined as a level below 2ong/ml. Risk factors for susceptibility include, obesity 11, smoking, a high skin phototype 33 , insufficient sun exposure and age 34. With age, the skin produces less of precursor 7-dehydrocholesterol in the epiderms, intestinal absorption of vitamin D declines due to a reduction in the number of vitamin D receptors (vdr) in enterocytes, and the body's ability to hydrolase vitamin $\mathrm{D}$ in the liver and kidney also decrease 11 . Some clinical conditions predispose to inadequate vitamin D level 35 as chronic liver disease, osteoporosis, hyperparathyroidism.

Anther risk factor is long term treatment drugs include anticonvulsants, antiretroviral, rifampicin, hormonal treatments. Vitamin $\mathrm{D}$ has been implicated in the pathogenesis and treatment of wide 
variety of skin diseases Psoriasis 36, atopic dermatitis, Acne. Value above $30 \mathrm{ng} / \mathrm{ml}$ of serum vitamin $\mathrm{D}$ be essential for maintain good health. Blood level above $200 \mathrm{ng} / \mathrm{ml}$ are considerable toxic so most medical societies consider $25(\mathrm{OH}) \mathrm{D}$ level is high than 125 to $150 \mathrm{ng} / \mathrm{ml}$ to be undesirable in order to avoid the adverse effects of vitamin D. Obesity is known to significantly affected both skin and systemic physiology, with growing numbers of obsess patients, it will increasing important for dermatologists to be able to modify and adapt topical and systemic dermatosis ${ }^{8}$ therapy for obese patients. It is important to know drug induced weight gain is also have a side effect for many medications prescribed by dermatologists. ${ }^{37}$ this view should be point to toxic effect made by these drugs. although obesity is a major public health problem, little attention has been paid to the impact of obesity on the skin. ${ }^{38}$ Drug-induced weight gain is also a significant side effect of many medications commonly prescribed by dermatologists. such weight gain can lead to patient noncompliance as well as exacerbation of comorbid conditions related to obesity. Medications that promote weight gain include, corticosteroids, oral-histamines, oral contraceptives, antidepressants as amitriptyline, serotonine retake inhibitors, as mirtazapine and paroxeline..$^{37,38}$

Constant nutritional monitoring in regular use of antiretroviral therapy drugs is necessary in order to prevent complication in the nutritional status with immune deficiency virus patients 38 . Obesity is responsible for a variety of changes in the skin physiology and a wide spectrum of dermatologic diseases. So dermatologists must work with primary care physicians and patients to reduce the detrimental effects of obesity on the skin.

\section{Further directions should be made towards nervous sys- tem and skin}

when stimulate nervous system, nerve fibers release neuromodulators of different chemical origin, predominantly peptides, which targets skin cells, expresses specific neuropeptide receptors. The homeostasis is accompanied by peptidases which degraded neuropeptides, neurotrophins that influence innovation and receptor expression in ganglia of primary effect neurons. ${ }^{39}$ The bidirectional of communication between skin cells and nervous system act as a homeostatic unit as guarantee regulation during physiological and pathophysiological states.

Important questions about physiological and pathophysiological role of nerves in skin function is still have to be elucidated, as how neuropeptide regulated, their receptors regulated and potential dysregulation in disease states. Also, neuropeptide degrade-enzymes are crucial point for skin function, which factors influenced these enzymes ${ }^{40}$ during inflammation, pain, pruritus. Finally, the use of morphological, molecular, and pharmacological techniques along with new genomic and proteomic approaches will lead to an integrated-understanding of the skin as a neuro immune endocrine organ during health ${ }^{41}$ and disease. hopefully to new and innovative approaches for the treatment of many skin diseases that still need to be cured. ${ }^{42}$

TRP-transit receptors potential ion channels contribute to cutaneous thermosentation-OSMO regulation- inflammation-and cell growth. Under pathological conditions such as inflammation of tissue injury, ${ }^{43}$ TRP are ultimately involved in signaling painful, and pruritus', stimulate to the CNS, thus identify of ion channels that detect heat or cold is non provide insight into molecular basis of neurogenic inflammation, pain, pruritus, may also be way to detect heat in case of covid 19. Disinvitation, this is caused by TRP V1-mediated depletion of neuronal-derived neuropeptides within certain subdivision of sensory nerves. ${ }^{44}$ Finally, enkephalins are reduced in parallel with improve induced by a topical vitamin D analog and corticosteroids, this point may be given great relation between enkephalins, vitamin D, covid 19 and hoping many researches be made on this area will be helpful. Also, association between dermatologic disease with vitamin D level and sensory modulator receptors in subcutaneous of skin should take in great attendance to understand and get new hopeful treatment.

\section{Acknowledgments}

None.

\section{Funding}

None.

\section{Conflicts of Interest}

Author declares that there is no conflict of interest.

\section{References}

1. Paul AJK, Arhp c CG, Aprn BC. Anatomy and physiology of the skin. JDNA. 2011;3(2):203-313.

2. Kanitakis J. anatomy, physiology and immunohistochemistry of normal human skin. European J of Dermatology. 2002;12(4):390-401.

3. Danby FW. Why we have sebaceous glanda. Journal of the American Academy. 2005;52(6):1071-1072.

4. Jame WD, Berger TG, Elston DM. Andrews diseases of the skin. Clinical dermatology. $10^{\text {th }}$ ed. Philadelphia: Elsevier Saunders; 2006.

5. Michael FH, Tai CC, Edward S. vitamin D and skin physiology. Journal of bone and mineral research. 2007;22:v28-v33.

6. Holick MF. Phylogeneric and evolutionary aspects of vitamin D from phytoplantkton to human. In: pang PKT, Schreibman MP editors. Vertebrate endocrinology: fundamentals and biomedical implications. Academic press. Orlando, FL, USA. 1986;3:7-43.

7. Holick MF. Vitamin D a millennium prespective. J Cell Biochem. 2003;88:296-307.

8. Gil Y, Amy D, Aerlyn D. Obesity and the skin: skin physiology and skin mainfestations of obesity. American Academy of dermatology. 2007;56(6):901-916.

9. Baskin ML, Ard J, Franklin F, et al. Prevalence of obesity in the United States. Obesity Rev. 2005;6(1): 5-7 
10. Loffler H, Aramaki JU, Effendy L. The influence of body mass on skin susceptibility to sodium lawryl sulphate. Skin Res Technol. 2002;8(1):19-22.

11. Narvarro FG, Arias Santigo S, Gilaberte Calzada Y. Vitamin D and the skin. Actas Dermosifiliogr (Engl Ed). 2019;110(4):262-272.

12. Andoh T, Kuraiashi Y. Direct action of immunoglobin G on primary sensory neuron through FC gamma receptor 1. FASEB J. 2004;18(1):182184.

13. Thompson JM, Mirza MA, Park AA, et al. The role of micronutririents in alopecia areata. AM J Clin Dermatol. 2017;18(5):663-679.

14. Stander S, Gunzer M. Metze D, et al. Localization of micro- opioid receptor IA on sensory nerve fibers in human skin. Regul Pept. 2002;110(1):75-83.

15. Groneberg DA, Welker P, Fisher TC, et al. Down regulation of vasoactive intestinal polypeptide receptor expression in atopic dermatitis. $J$ Allergy Clin Immunol. 2003;111(5):1099-1105.

16. Delagado M, Pozo D, Ganea A. The significance of vasoactive intestinal peptide in immunomodulation. Pharmacol Rev. 2004;56(2):249-290.

17. Gonzalez Ray E, Delgado M. Role of vasoactive intestinal peptide in inflammation and autoimmunity. Curr Opin Invest Drugs. 2005;6(11):1116-1123.

18. Veljkosvic V, Metlas R. Application of VIP/NTM-reactive natural antibodies in therapy of HIV disease. Int Rev Immunol. 2004;23:437-445.

19. Jongsma H, Pettersson LM, Zhang Y, et al. Marketly reduced chronic nociceptive response in mice lacking the PAC1 receptor. Neuroreport. 2001;12(10):2215-2219.

20. Armstrong BD, Abad C, Chith S, et al. Restoration of axotomy-induced PACAP gene induction in SCID mice with CD+4 T-lymphocytes. Neuroreport. 2004;15(17):2647-2650.

21. Brenneman DE, Philips TM, Hauser J, et al. Complex arrary of cytokines released by vasoactive intestinal peptide. Neuropeptide. 2003;37(2):111-119.

22. Solbrig MV, Koob GF. Epilepsy CNS viral injury and dynorphin. Trends Pharmacol Sci. 2004;25(2): 98-104.

23. Fizanne L, Sigaudo Roussel D, Saumet JL, et al. Evidence for involvement of VAP1 and VAPC2 receptors in pressure-induced vasodiliation in rodents. J Physiol. 2004;554(2):519-528.

24. Delgado M, Reduta A, Sharma V, et al. VIP/PACAP oppositely affects immature and mature dendritic cell expression of CD 80/CD 86 and the stimulatory activity for CD 4 T cells. J Leuko Biol. 2004;75(6):11221130.

25. Bigliardi Qi M, Lippo B, Sumanovski LT, et al. Changes of epidermal mu- opiate receptor expression and nerve ending in chronic atopic dermatitis. Dermatology. 2005;10(2):91-99.

26. Bigliardi Qi M, Sumanoviski LT, Buchner S, et al. Mu- opiate receptors and beta-endophrin expression in nerve ending and keratinocytes in skin. Dermatology. 2004;209(3):183-189.
27. Bigliardi PL, Bucher S, Rufli T. et al. Specific stimulation of migration of human keratinocytes by mu- opiate receptor agonist. J Recept Signal Transduct Res. 2002;22(1-4):191-199.

28. Hasan W, Zhang R, Liu M, et al. Coordinate expression of NGF and alpha-smmoth actin mRNA and protein in cutaneous wound tissue of developing and adult rats. Cell Tissue Res. 2000;300(1):97-109.

29. Kanda N, Watanabe S. 17beta-estradiol enhances the production of nerve growth factors in THP-1 derived macrophages. J Invest Dermatol. 2003;121(4):771-780.

30. Manni L, Lunderberg T, Tirassa P, et al. Cholecystokinine-8 enhances nerve growth factors synthesis and promotes recovery of caspasiacin-induced sensory deficit. BrJ Pharmacol. 2000;129(4):744-750.

31. Bergman E, Ulfhake B, Fundin BT. Regulation of NGF-family ligands and receptors in adult nervation. Eur J Neurosci. 2000;12(5):26942706.

32. Grant WB. An estimate of premature cancer mortality in the US. Due to inadequate doses of solar ultraviolet-B-radiation. Cancer. 2002;94(6):2861-2869.

33. Xiang F, Iucas R, De Griijl F, et al. A systematic review of the influence of skin pigmentation on changes in the concentration of vitamin $\mathrm{D}$ and 25-(OH)D in serum following experimental UV-irradiation. Photochem Photobiol Sci. 2015;14(12):2138-2146.

34. Reyes Garcia R, Garcia Martin A, et al. Update of recommendations for evaluation and treatment of osteoporosis associate to endocrine and nutritional conditions. Endocrinol Nutr. 2015;62(5):e47-e56.

35. Whittier X, Saag KG. Glucocorticoid -induced osteoporosis. Rheum Dis Clin North Am. 2016;42:177-189.

36. Bergler Czop B, Brzezinska Wcislo L. Serum vitamin D level the effect on the clinical cause of Psoriasis. Postepy Dermatol Alersol. 2016;33(6):445-449.

37. Ness-Abramof R, Apovian CM. Drug induced weight gain. Timely Top Med Cardiovas Dis. 2005;9: E31.

38. Herika de cassia ADB. Nutritional profile of patient with aquired immmunodefience syndrome. 2021;5:42.

39. Ibrahim MM, Porreca F, Lai J. CB2 cannabinoiod receptors activation produces antinociceptive by stimulating peripheral release of endogenous opioids. Proc Nalt Acad. 2005;102(8):3093-3098.

40. Johnson GD, Stevenson T, Ahn K. Hydrolysis of peptide hormones by endothelin converting enzyme -1 .a comparison with neprilysin. J Biol Chem. 1999;274:4053-4058.

41. Szolcsanyi J, Sandor Z, Petho G, et al. Direct evidence for activation and desenisation of the capsaicin receptors by $\mathrm{N}$ - oleoyldopamine on TRPV1 -transfected cell line in gene deleted mice and rats. Neurosci Lett. 2004;361(1-3):155-158.

42. Couture B, Adam F, Willer JC, et al. Hyperalgesis and allodynia prepheral mechanism. Joint Bone Spine. 2005;72(5):359-371.

43. Holzer P. Neurogenic vasodiliation and plasma leakage in the skin. Gen Pharmacol. 1998;30(1):5-11. 